\title{
O impacto da corporeidade nos escritos de Catharine MacKinnon na década de $1990^{1}$
}

\author{
Magda Guadalupe dos Santos²
}

\begin{abstract}
Resumo: As teorias feministas de Catharine MacKinnon sobre a questão do corpo, na década de 1990, ampliam as discussões que regulam o processo de materialização de significados e submissão das mulheres ao poder. MacKinnon, especialmente em Are Women Human?, propõe que se amplie a proteção das mulheres contra a violência, visando alcançar, nos julgamentos de estupros em tempos de guerra, a conotação de genocídio, pelo seu impacto ético-político. Também com relação à pornografia ela é profundamente crítica, entendendo isso como verticalidade de uma violência explícita que deveria ser combatida. Ao se questionar o alcance de sua teoria no momento histórico de sua produção, verifica-se que suas preocupações chegam até os dias atuais em novas pautas axiológicas, mas ainda como um desafio e uma necessidade teórica nos tópicos feministas da atualidade.
\end{abstract}

Palavras-chave: Catharine MacKinnon - Corporeidade - Feminismos - Humanidade - Violência

\section{The impact of corporeality on Catharine MacKinnon's writings in the 1990s}

\begin{abstract}
Catharine MacKinnon's feminist theories of the 1990s on the issue of the body broaden discussions about the process of materializing meanings and submitting women to power. MacKinnon, especially on Are Women Human? proposes to expand the protection of women against violence, aiming to achieve genocide connotations in rape trials in times of war, due to their ethicalpolitical impact. The pornography scene is also deeply criticized by her, as the verticality of an explicit violence that should be combated. When questioning the scope of her theory at the historical moment of its production, it appears that her concerns reach the present day in new axiological guidelines, but still as a challenge and a theoretical necessity in feminist topics today.

Key words: Catharine MacKinnon - Corporeality - Feminisms - Humanity - Violence

\footnotetext{
${ }^{1}$ Este artigo foi apresentado, numa primeira versão, sob o título de $A$ herança de Simone de Beauvoir nos temas da corporeidade em Catharine MacKinnon e Judith Butler, no II Encontro do GT Filosofia e Gênero, ocorrido na Universidade de São Paulo, de 4 a 6 de setembro de 2019, organizado pela Profa. Silvana de Souza Ramos. Ter ali na USP a oportunidade de conversar sobre teorias feministas foi uma honra, especialmente em tempos tão sombrios.

2 Professora Adjunta do Departamento de Filosofia e da Faculdade de Direito da Pontifícia Universidade Católica de Minas Gerais (PUC Minas) e da Faculdade de Educação da Universidade Estadual de Minas Gerais (FaE-UEMG). Advogada. Mestre em Filosofia e Doutora em Direito pela Universidade Federal de Minas Gerais (UFMG). Pesquisadora de Teorias Feministas, Questões de Gênero e Filosofia Feminista. E-mail: magda.guadalupe@yahoo.com.br
} 


\section{Introdução}

As análises dos feminismos contemporâneos conduzem a várias trilhas indagativas que ampliam afirmativamente os caminhos que viabilizam a vida das mulheres, a partir de reflexões sustentadas e amparadas pelas questões e causas feministas. O controvertido panorama das teorias feministas tem sido tratado como um movimento aberto, não unitário, com grande mobilidade histórica. Sendo distintas as leituras feministas em suas várias vertentes, alguns temas, como o da corporeidade e seu impacto nas interpretações temporalizadas, tornam-se palco de teorizações e práticas que perpassam a vida das mulheres nos seus enfrentamentos cotidianos. Seja para realçar diferenças de gêneros ou procurar igualdades relacionais, o corpo sempre conta como algo determinante na vida de mulheres, em torno ao questionamento sobre o sentido de sua materialidade. Neste propósito, voltase ora a questionar direções menos opressivas de validade dos corpos de mulheres, para além das idealizações de perfeição, utilidade e validade como determinações patriarcais.

O debate sobre a questão corpórea tornou-se bastante relevante na década de 1990, devido a um rol de publicações motivadas por vivências em cenários de embates sociais e políticos. Entre os acontecimentos mais marcantes, tem-se a consolidação dos governos democráticos liberais, com o suporte do capitalismo global, assim como o aumento nos casos de AIDS, a guerra dos Bálcãs, o genocídio de Ruanda e a primeira Guerra do Golfo, além do aumento da violência nos grandes centros urbanos. Em todos os eventos, o corpo das mulheres contava como objeto de degradação e violência, de morte, mas também de luta.

Nesse período, na vertente pós-estruturalista, Judith Butler, particularmente em Bodies that Matter, de 1993, investiga as condições de possibilidade para que os corpos importem, no contexto das normas discursivas e sociais de submissão ao poder. Na complexa relação entre poder e discurso, instituem-se teorias e práticas acerca dos corpos, especialmente femininos, que se redefinem na performatividade discursiva da sexualidade e na configuração de uma vida viável.

Segundo M. L. Femenías, ao reconhecer o duplo significado de "matter", tanto como matéria, quanto como importância, Butler ressalta a hipótese do corpo como "meio ou instrumento no qual se inscrevem os significados culturais" ", num processo de materialização das normas regulatórias, pelas quais o sexo não é apenas uma descrição estática, mas aquilo que vem qualificar o corpo e passa a inscrevê-lo em "um domínio de inteligibilidade cultural"4.

De outra perspectiva, realçando a multiplicidade de vozes dos feminismos, Catharine MacKinnon, especialmente em Only Words, de 1993, problematiza a subordinação dos corpos das mulheres pela violência pornográfica. Já em Are Women Human? and Other International Dialogues, coletânea de artigos dos anos 1990, publicada em livro somente em 2006, ela advoga a favor das mulheres violentadas em massa na Guerra do Kosovo. No embate teórico sobre a corporeidade, para MacKinnon as mulheres são tomadas como um produto de desigualdade sexual e, por isso, são objeto de violência contínua.

${ }^{3}$ FEMENÍAS, Judith Butler. Introducción a su lectura, pp. 57-58.

${ }^{4}$ BUTLER, Bodies that Matter. On the Discursive Limits of Sex, p. 4. 
A proposta deste artigo é abordar a questão da corporeidade na obra de Catharine MacKinnon, priorizando os trabalhos publicados nos anos 1990, pois muito contribuem para pensar os corpos das mulheres no cenário atual.

Vale observar que, desde a publicação de O Segundo sexo, em 1949, por Simone de Beauvoir, se reconhece que um corpo não nasce, ele se torna um corpo em um processo complexo e indefinido. Não mais perdura, assim, a ilusão de uma origem corpórea fixa e de uma conclusão espaço-temporal que encerraria com precisão os detalhes da vida ${ }^{5}$. $\mathrm{O}$ ato de tornar-se uma mulher não é algo linear, simples tópico sequencial de dados naturais ou biológicos incontestáveis. O questionamento do que seja o natural, o cultural, o real e o feminino traz à cena, das várias leituras interpretativas, distintas possibilidades de entendimento sobre as relações entre poder e discurso.

\section{O tema da corporeidade nas obras dos anos 1990}

No contexto histórico e das estruturas de poder na década de 1990, alguns tópicos se mostram relevantes nas obras de Catharine MacKinnon, especialmente em Only Words e Are Women Human?

\section{Estupros na forma de genocídio}

MacKinnon responde aos anseios de igualdade jurídica entre os gêneros e problematiza o lugar ocupado pelas mulheres na guerra e, para além da guerra, sob o impacto midiático. Tendo seguido os problemas vividos pelas mulheres na Guerra do Kosovo, no final dos anos 1990, inclusive como advogada de algumas ONGs canadenses, ela insistiu no pedido de que a Corte Internacional considerasse como genocídio os estupros generalizados de mulheres bósnias e croatas ${ }^{6}$. Naquele momento, denunciava ela que o uso do estupro generalizado durante a guerra tinha como intenção ampliar de forma enfática a violência contra as mulheres em geral. Diante dessas violações, "a lei dos direitos humanos precisaria de efetiva revisão", para que a negação da humanidade das mulheres não provocasse danos essenciais nos direitos humanos, baseados justamente em sexo e etnia. Ela insiste na função do estupro como uma ferramenta comum ou usual de subordinação das mulheres e também como uma arma de genocídio aproximando os genocídios historicamente reconhecidos, desde o Holocausto, ao genocídio quotidiano de mulheres.

Conforme MacKinnon, o ato de se tornar um ser humano, "tanto em termos jurídicos, quanto em função do alcance e sentido da vida vivida", equivale a um processo social, jurídico e político, a um complexo devir. Isto exige que proibições sejam estipuladas e deslegitimados os atos mediante os quais seres humanos são violados. Tal invalidação deveria ser reconhecida para a garantia de uma existência plenamente humana e, em consequência, para que se preservassem formalmente (officially upholding) essas normas, tornando exigíveis os direitos (entitlements) daí decorrentes. ${ }^{7}$

\footnotetext{
${ }^{5}$ BURGOS DÍAZ, “Cruzando líneas. Trazando conexiones”, p. 332.

${ }^{6}$ MACKINNON, Are Women Human? and Other International Dialogues, pp. 41-43.

${ }^{7}$ MACKINNON, Are Women Human? and Other International Dialogues, p. 2.
} 
Todavia, para que pudesse haver "reparação e proteção" era preciso, antes de tudo, que grupos subordinados fossem reconhecidos como reais em relação ao poder, sendo vistos como "grupos de seres humanos". Segundo McKinnon, Mulheres não são ideias, mas são reais, conforme alega ela também em Only words. Os direitos humanos devem ser sempre a resposta às atrocidades praticadas contra as mulheres e tais perversidades devem ser reconhecidas enquanto tal, recusando-se a leitura autoritária que as minimiza, ao afirmar que são "demasiadamente extraordinárias para que nelas se acredite ou muito comuns para serem tomadas como atrozes"s.

\section{A Humanidade das Mulheres seria possível?}

No primeiro dos textos que compõem a coletânea Are Women Human?, o qual constituía originalmente uma curta exposição acerca da efetividade da Declaração universal dos direitos humanos, MacKinnon desenvolve uma forma bastante realista de apontar os problemas:

$\mathrm{Na}$ Declaração dos direitos humanos, de 1948, está definido o que é um ser humano, assim como os seus direitos. Já se passaram mais de 50 anos. As mulheres são humanas? Se nós, mulheres, fôssemos humanas, seríamos transportadas como mercadorias prontas a sermos vendidas da Tailândia aos bordéis de Nova York? Seríamos escravas sexuais, usadas para finalidades reprodutivas? Seríamos criadas como animais, constrangidas a trabalhar por toda a nossa vida sem sermos pagas? (...) Seríamos mortalmente agredidas, ou quase, pelos homens dos quais somos íntimas? Seríamos sexualmente molestadas no interior de nossas famílias? Se nós, mulheres, fôssemos humanas, a nossa violação seria louvada por nossos violadores??

Segundo Antonella Besussi e Alessandra Facchi, organizadoras da edição italiana e comentadoras do livro, o que se afirma é quanto se moldam de forma hierárquica as relações entre mulheres e homens, dividindo superiores e inferiores, e sexualizando a desigualdade, para que permaneça o domínio patriarcal. ${ }^{10}$ Contudo, as diferenças sexuais não parecem a MacKinnon explicativas da questão da divisão do poder, da vulnerabilidade das mulheres e de sua exclusão dos atos decisórios dos homens. Os termos utilizados pela autora, constrangimento, humilhação, exploração e violação enfatizam a relação de desigualdade entre os gêneros, apontando aquilo que deve ser combatido.

De acordo com as comentadoras italianas, a posição de MacKinnon em Are Woman Human? é realista não somente no sentido comum do termo, como também enquanto afirma que as mulheres devem participar ativamente da realidade e não apenas recontá-la. Deparase aqui também com um sentido filosófico, na medida em que MacKinnon indica um mundo exterior que independe das mulheres e que resiste às tentativas de transformação. De acordo

\footnotetext{
${ }^{8}$ MACKINNON, Are Women Human? and Other International Dialogues, p. 3.

${ }^{9}$ MACKINNON, Are Women Human? and Other International Dialogues, pp. 41-42. Veja a tradução completa do texto publicada em VirtuaJus. Revista eletrônica. PUC Minas. v. 5, n.o 8, 2020.

${ }^{10}$ BESUSSI; FACCHI, 2014.
} 
com seu estilo pragmático, no entanto, apenas as implicações políticas desta tese filosófica lhe interessam ${ }^{11}$.

Já no prefácio da própria obra pode-se ler como as mulheres são por MacKinnon comparadas a um "povo" que não pode ser reconhecido como tal porque a violência masculina as golpeia enquanto mulheres, impedindo-as de perceberem-se como grupo. Nessa lógica, sua liberdade sexual não existe e não pode existir, até que o "domínio masculino" seja derrubado como sistema de opressão. Também as categorias "homem" e "mulher" são estruturadas como "relações de domínio hierárquico", são fruto de erotização e de relações de dominações ${ }^{12}$. O poder masculino se organiza em torno a uma política do sexo e se vale da prática da violência sexual, com fundamento ideológico na misoginia.

A categoria "mulher" não é, em MacKinnon, simplesmente um "outro", como pode ser lido amplamente em Simone de Beauvoir, mas um "outro erotizado e sexualmente submetido", um "outro" reificado e transformado em objeto sexual por meio do qual o opressor pode satisfazer seu próprio desejo. Todo o seu trabalho demonstra que a compreensão do humano não estará completa até que as mulheres possam contribuir para torná-lo compreendido também como algo ao qual se integram.

No conjunto dos artigos de Are Woman Human?, o que as mulheres fazem, sentem e dizem é real. O tom de MacKinnon, neste ponto, não é moralista, mas bastante pragmático, visando cercar de frente os acontecimentos. A referência a um critério de realidade é relevante para que se possa entender o modo como ela se orienta nas passagens descritivas dos textos. Evidencia-se a descrição de uma violência coativa em relação às mulheres em tempo de guerra e em períodos de paz. Mackinnon tem como base a realidade dos dados que revelam as vítimas de assédio sexual, estupro, feminicídio e, sobretudo, as vítimas da pornografia, configurando uma violência não apenas simbólica, mas também material contra as mulheres. Desse modo, ela trabalha vários espaços de violência que incidem nos corpos de mulheres, que delas retiram seu cunho de humanidade, o que leva à seguinte indagação: quando fatos de violência política - amplamente pensada - incidem sobre as mulheres, que tipo de direitos humanos se tem no projeto histórico da humanidade? O que se entende por direitos humanos quando se analisam os problemas das mulheres na guerra e para além da guerra? ${ }^{13}$

É possível pensar que o que MacKinnon critica é o fato de que o universalismo dos direitos humanos sempre se forjou à luz do homem, masculino, branco? Estaria ela indicando a necessidade de abandonar a pretensão de universalidade dos direitos humanos, tal como Wendy Brown ironicamente cogita, julgando tratar-se de uma "defesa pura dos inocentes e dos impotentes frente ao poder", contra as "imensas maquinarias potencialmente cruéis ou despóticas da cultura"? ${ }^{14}$ Em MacKinnon o que se encontra é algo mais objetivo; ela faz realçar que tais "direitos humanos" integram certa ideia de ser humano substancial e masculinamente descrita. Os direitos humanos são produtos de uma relação conflitiva entre uma lógica social de dominação e uma lógica de oposição à dominação. Tais direitos não respondem a práticas e experiências particulares das mulheres. ${ }^{15}$

\footnotetext{
${ }^{11}$ BESUSSI; FACCHI, Introduzione all'edizione italiana di: Le donne sono umane?, p. 3.

12 MACKINNON, Are Women Human? and Other International Dialogues, p. 3.

${ }^{13}$ Cf. MACKINNON, Are Women Human? and Other International Dialogues.

${ }^{14}$ BROWN, “The Most We Can Hope For...': Human Rights as the Politics of Fatalism” p. 453.

${ }^{15}$ CASTILLO, "Lo humano, la violência y las mujeres", p. 35.
} 
MacKinnon aponta haver uma ausência no âmbito da universalidade dos princípios dos direitos humanos, a ausência do corpo sexuado, cuja presença infundiria neles um senso de realidade e de verdadeiro alcance da cidadania, erradicando-se a violência sexual contra as mulheres. A sua proposta seria a de avançar na temática dos direitos humanos, problematizando se haveria ali lugar para emoções, novos corpos, novos sofrimentos na construção das leis ${ }^{16}$.

\section{A violência da pornografia}

Para além do cenário de guerra, o que mais se tem destacado nos debates sobre os textos de Catharine MacKinnon são suas posições teóricas e práticas sobre a questão da pornografia, que muito tem dividido os entendimentos feministas desde o final do século XX. Desde Feminism Unmodified, de 1987, Pornography and Civil Rights: A New Day for Womens Equality, de 1988, e, especialmente, Only Words, publicado em 1993, MacKinnon define a pornografia como uma forma de subordinação feminina sexualmente explícita. Seus elementos desumanizam as mulheres e as tomam como meros objetos sexuais, em que incidem dor e humilhação, prazer na violação, que se expressam visual e graficamente em posição de inferioridade. A seu sentir, a mídia pornográfica, que serve à sociedade patriarcal e com ela sempre muito lucra, trabalha a pornografia como um discurso estigmatizante que reproduz condutas sexuais ditas "normalizadas", visando nada mais do que dominação, opressão e reificação das mulheres, num processo de comunicação, nos termos de Alessandra Facchi, "que se desenvolve em condições de desigualdade"17.

Conforme MacKinnon, o que a pornografia produz é um contínuo de violências erotizadas, apresentadas como algo desejável pelas fictícias mulheres representadas pela mídia, e cujo preço é sempre pago pelas mulheres reais, especialmente, nos cenários da violência doméstica. Este espaço de suposta autonomia privada se apresenta como objeto de desinteresse do direito público - expresso na ausência de proteção às mulheres contra as discriminações que ocorrem nas famílias, conforme o entendimento de Rhonda Copelon ${ }^{18}$ e a pornografia adentra também os lares pela vivência e dominação masculina. Em MacKinnon, tais vivências mantêm-se como uma forma de prática de política sexual, uma instituição da desigualdade dos sexos. De tal perspectiva, a pornografia não constitui uma fantasia inofensiva ou um mero espetáculo, mas se revela, juntamente com as formas de violação e de prostituição das quais participa, como uma construção social dos gêneros, em que a erotização da dominação e da submissão se funde à sexualidade da supremacia masculina.

Mackinnon escreve em Only Words como a mídia pornográfica usa ou mesmo abusa das mulheres, tomando-as como simples objeto de manuseio sexual e eximindo-se de quaisquer responsabilidades, sob a alegação de que se está diante de simples ideia ou metáfora do sexo. Seus argumentos de contestação são enfáticos: "nos limites dessa abordagem, dizer que a pornografia é um ato contra as mulheres é visto como metafórico ou mágico, retórico

\footnotetext{
16 CASTILLO, "Lo humano, la violência y las mujeres", p. 38.

${ }^{17}$ FACCHI, "El Pensamiento Feminista sobre el Derecho. Un recorrido desde Carol Gilligan a Tove Stang Dahl”, p. 27.

${ }^{18}$ COPELON, “Terror íntimo: violencia doméstica entendida como tortura”, 1997, p. 112.
} 
ou irreal, uma hipérbole literária ou um dispositivo de propaganda" ${ }^{19}$. Defender a pornografia como "simples palavras" (only words) é desvinculá-la de seu "referencial de realidade", mesmo quando a mídia utiliza fotos que revelam como as mulheres foram por ela usadas, quando a matéria escrita "são os próprios corpos das mulheres, mesmo quando uma mulher é destruída para dizer ou mostrar" o que a indústria pornográfica quer que seja dito ou mostrado ${ }^{20}$.

\section{Liberdade de expressão}

A questão central que se debate em Only Words diz respeito ao entendimento jurisprudencial acerca da Primeira Emenda da Constituição norte-americana, a proteção da mídia pornográfica encontrando respaldo na expressão "the freedom of speech, or of the press" 21 . De certa interpretação conservadora, referendada, contudo, nos termos constitucionais, obliteram-se meios de apontar como afrontoso à dignidade das mulheres o tratamento de violência que a indústria pornográfica lhes confere. Quando as imagens, que, na verdade, são "discursos protegidos", expressam violência, a Primeira Emenda é invocada para satisfação e proteção do nefasto repertório das mídias de pornografia.

Nos Estados Unidos, a pornografia é protegida pelo Estado ao preço de silenciar as mulheres violadas e ainda fazer identificar o abuso com uma ideia ou um ponto de vista do que se pensa sobre as mulheres e sobre o sexo. Contudo, escreve MacKinnon, "o que a pornografia faz", ela o "faz no mundo real" e não apenas como simples idealidade ${ }^{22}$. O que se pode ver na indústria pornográfica não são as ideias que suas matérias expressam, mas o efeito de chantagens, pressões e truques, formas de persuasão das mulheres para fazer sexo sob o impacto da violência e serem então fotografas em situações aviltantes. Em seus próprios termos, "Na pornografia, as mulheres são estupradas por gangues para que possam ser filmadas. Elas não são estupradas por gangues pela ideia de estupro. É para a pornografia, e não pelas ideias contidas nela, que as mulheres são feridas e penetradas, amarradas e amordaçadas, despidas para que as fotos de sexo possam ser feitas."23

Quando as mulheres são também mortas para satisfazer as exigências do filme de sexo, não é a ideia de um assassinato sexual que as mata, é a ação da indústria pornográfica em si mesma que incide brutalmente contra os corpos das mulheres. Além disso, a projeção da mídia, sobre as transformações no sistema patriarcal, faz com que as agressões na vida real, no âmbito doméstico e de trabalho, sejam efeitos do modo como os homens que se utilizam da pornografia são por ela afetados e impelidos a violência. Ironicamente, segundo MacKinnon, não são simples ideias que ali se expressam. É necessário fazer alguma dessas coisas para expressar, não apenas com ideias, as ideias que a pornografia expressa, já que "a pornografia não sai da prateleira e agride as mulheres", mas as consequências de suas atividades o fazem: "o que acontece através do seu uso que é o problema". ${ }^{24}$

\footnotetext{
${ }^{19}$ MACKINNON, Only Words, p. 12.

${ }^{20}$ MACKINNON, Only Words, pp. 12-15.

21 The First Amendment text reads: "Congress shall make no law respecting an establishment of religion, or prohibiting the free exercise thereof; or abridging the freedom of speech, or of the press; or the right of the people peaceably to assemble, and to petition the Government for a redress of grievances."

22 MACKINNON, Only Words, p. 14.

${ }^{23}$ MACKINNON, Only Words, p. 15.

${ }^{24}$ MACKINNON, Only Words, p. 15.
} 
A proposta de MacKinnon não se manifesta somente como crítica teórica, mas se apresenta por meio de alternativas ao entendimento convencional da lei, para que se redefina a pornografia como material gráfico sexualmente explícito que subordina as mulheres por meio de figuras ou palavras ${ }^{25}$. Suas ações correspondem a orientações a projetos de leis que possam combinar "o que se apresenta graficamente como sexualmente explícito", com atividades que se expressam em atos de "ferir, degradar, violar e humilhar" as mulheres; propõem-se alternativas hermenêuticas para que se evidencie ser ultrajante a forma como a indústria pornográfica tem subordinado ativamente as mulheres, ao tratá-las "de modo desigual, como algo menos que humano, com base no sexo" ${ }^{26}$. É que a pornografia não se restringe ao que é dito, mas se delimita no que faz, nem é protegida porque diz algo, mas em relação ao que faz ${ }^{27}$.

O entendimento da Suprema Corte norte-americana é de que não se pode restringir a liberdade de expressão pelo que é dito, contudo, segundo MacKinnon, "toda expressão restrita diz algo" (all restricted expression says something) ${ }^{28}$. A negação de que a pornografia é uma força real vê-se disfarçada em muitas construções midiáticas. Diz-se que, no máximo, a pornografia reflete, descreve ou representa a subordinação que ocorre alhures (that happens elsewhere). Comumente, afirma-se que a pornografia é mera "fantasia", significando algo "irreal ou apenas uma realidade interior". Contudo, indaga MacKinnon, "para quem?” As mulheres podem ser delas dissociadas, mas as degradações ocorrem em seus corpos. Aqueles que consomem a pornografia se utilizam de corpos de mulheres de forma regular e não como mera fantasia! As projeções reais ocorrem sob o impacto da pornografia e as cenas são revividas com mulheres reais, com as quais se vive e muitas das quais são levadas à morte ${ }^{29}$.

Em seu entendimento, não se trata de verificar se o Direito deve tratar as mulheres de modo idêntico ou diferente daquele deferido aos homens. A questão central é tentar evitar que o Direito se constitua como instrumento de subordinação e opressão. Verifica-se o confinamento das mulheres a papéis construídos pela cultura masculina, sendo preciso mudar tais bases de opressão, em que a sexualidade tem sido o âmbito privilegiado de violência presente na sociedade patriarcal. Nesse contexto, a pornografia que faz uso da violência contra as mulheres se traduz em efeitos sociais bastante nocivos a mulheres e a homens, e propõe imagens de humilhação das mulheres que repercutem em várias situações, na família, no trabalho. Neste sentido, a pornografia é considerada por ela como um instrumento da cultura masculina que alimenta a discriminação feminina, produzindo danos não apenas aos indivíduos singularizados que a ela se submetem, mas também às mulheres enquanto uma coletividade.

Nos Estados Unidos, trata-se, contudo, de algo debatido no plano dos princípios, já que coloca em campo de discussão, de um lado, a liberdade de expressão e a tutela proveniente da Primeira Emenda, de outro, a igualdade entre os sexos e, pois, os princípios estipulados na Décima Quarta Emenda, evocados também para a tutela protetiva das Mulheres (the equal protection of the laws). Se os debates nas cortes norte-americanas alegam proteger a liberdade de expressão, independentemente de cada juízo sobre seu conteúdo e

\footnotetext{
${ }^{25}$ MACKINNON, Only Words, p. 22.

${ }^{26}$ MACKINNON, Only $W$ ords, p. 22.

${ }^{27}$ MACKINNON, Only Words, p. 22.

${ }^{28}$ MACKINNON, Only Words, p. 23.

${ }^{29}$ MACKINNON, Only Words, p. 27.
} 
de suas possíveis consequências, toda vez que a pornografia é liberada toda tentativa de frear seus impactos incorre na declaração de inconstitucionalidade por parte do Poder Judiciário.

MacKinnon insiste em afirmar que gestos e imagens não são simples palavras. Se as palavras se referem à realidade e a pornografia é defendida apenas como palavras (mesmo quando se expressa como imagens), a violência e a destruição de corpos femininos deveriam ser sancionadas. Enquanto continua a prosperar o entendimento das cortes, a mídia pornográfica se mantém livre em suas expressões de violência, não se podendo taxá-la como crime. Merecem ser ampliados os meios protetivos contra as ofensas sexuais no trabalho, na vida privada para que se promova uma transformação social mais profunda ${ }^{30}$.

\section{Autonomia e escolha}

Realmente, parece não haver, neste contexto de abordagem da pornografia, nenhum espaço de agenciamento ou mesmo de resistência das mulheres, e tal fato tem sido criticado por outras alas dos feminismos contemporâneos ${ }^{31}$. Seja porque, para MacKinnon, a mídia impede as mulheres de se dotarem de autonomia de escolha para recusar participar do cenário real da subordinação pornográfica, seja pelas questões sociais e políticas que não favorecem a autonomia das mulheres e as utilizam como mero objeto sexual violentado. Contudo, no contexto da força política dos feminismos contemporâneos, Cláudia de Lima Costa, na esteira de Teresa De Lauretis ${ }^{32}$, afirma que positividades têm sido construídas por seus sujeitos, com base na materialidade das experiências de mulheres em nível social. Surgem, segunda Costa, posições paradoxais ocupadas pelos sujeitos dos feminismos, tanto em termos de discursos e representações, quanto nas lutas sociais de maior amplitude. Tais representações não poderiam se situar apenas em repressões identitárias impostas pelo sujeito masculino, ${ }^{33}$ sendo necessário se repensar a contribuição epistemológica dos feminismos para a redefinição da subjetividade e sociabilidade, conforme De Lauretis ${ }^{34}$.

Contudo, seja de ótica construtiva ou crítica dos feminismos, o que Catharine MacKinnon indica é a economia simbólica e efetiva do patriarcado, campo que perpetua a impossibilidade de que as mulheres possam se ver em condições de sujeito de suas próprias histórias. O que ela visa é analisar as condições de vida de mulheres reais, para que elas possam escapar do que lhes é imposto e refazer a vida em novos campos de valor e sob a proteção constitucional. Não se trata de um essencialismo positivo, mas de uma preocupação com o seu teor de realidade e historicidade. Sua preocupação volta-se para uma teoria jurídica crítica e que possa problematizar métodos e categorias da ciência jurídica convencional e suas interpretações estigmatizantes ${ }^{35}$.

\footnotetext{
${ }^{30}$ MACKINNON, "Feminism, Marxism, Method and the State: Toward Feminist Jurisprudence”, p. 639.

31 No debate contra as teses de MacKinnon, apresenta-se Nadine Strossen, 1995, para a qual se está vivendo verdadeiro "pânico de sexo" (sex panic) como um falso alarme. O fato de tratar-se de uma expressão sexual não invalida a pornografia como algo contrário aos direitos das mulheres, sobretudo aos seus direitos de escolha.

32 De LAURETIS, Technologies of Gender: Essays on Theory, Film, and Fiction, pp. 23-24; De LAURETIS, "O sujeito no feminismo. Revisitando os debates", pp. 59-90.

33 COSTA, "O sujeito no feminismo: revisitando os debates", p. 64.

${ }^{34}$ De LAURETIS, Technologies of Gender: Essays on Theory, Film, and Fiction, p. 24.

${ }^{35}$ Se é mesmo realista ou por demais conservadora a posição de MacKinnon, isso seria um tema para um novo texto e novos debates teóricos.
} 


\section{Pornografia e violência de guerra}

Outra perspectiva pode ser considerada quando a violência pornográfica se agrega à violência da guerra, o que se discute no artigo intitulado "Turning Rape into Pornography: Postmodern Genocide" (1993), texto integrante do livro Are Women Human? Os relatos de mulheres sobreviventes da guerra na Sérvia relatam os estupros diários, também filmados. MacKinnon compara tais campos de estupros com os campos de concentração nazistas, com a especificidade de que, naquela guerra, estupros étnicos (etnic rape) ocorriam dia após dia, a prostituição sendo forçada regularmente e a pornografia surgindo como uma ferramenta de genocídio (pornography emerges as a tool of genocide) ${ }^{36}$.

Ela também insiste em indicar o grande uso da pornografia na antiga Iugoslávia, anteriormente à guerra dos Bálcãs. Quando os estupros generalizados se iniciaram, os soldados já estavam devidamente preparados para banalizar a situação, havendo integrado durante algum tempo as cenas de violência pornográfica em seu imaginário social ${ }^{37}$. A pornografia havia se tornado normalizada anteriormente à guerra, quando grande parte da população masculina se preparava para "desumanizar as mulheres" e para gozar do prazer de lhes infringir violências sexuais ${ }^{38}$. Para MacKinnon, a pornografia havia se tornado a perfeita preparação para a guerra, tal como um "manual de instrução e motivação para as atrocidades sexuais" (for the sexual atrocities) ordenadas naquele genocídio. A pornografia havia desumanizado as mulheres "para seus consumidores" (for its consumers), em forma de entretenimento $^{39}$. De fato, configura-se uma situação bastante constrangedora e apta a retirar das mulheres a sua dimensão de humanidade e autonomia, sem, entretanto, causar grande estranhamento ao mundo, pelo impacto do que ela denomina como "Double-edged denial", uma "dupla-negação", uma negação de dois gumes, ou uma negação com um sentido dúplice, segundo a qual o abuso das mulheres - como já se salientou - é considerado ou extraordinário demais para nele se acreditar, ou comum demais para ascender ao nível das violações protegidas pelos direitos humanos internacionais ${ }^{40}$.

Por força de lei ou por decisão judicial, "alguém é menos do que humano quando sua violação não remete aos direitos humanos que lhe são reconhecidos”. Atos corriqueiros na experiência de mulheres, como os estupros, têm sido desprezados, rebaixados e tornados invisíveis (beneath) em relação ao que é noticiado ou revelado como sério ou relevante. Enquanto descrença e impunidade prevalecem, "os sujeitos violados são transformados em seres não totalmente humanos, em termos jurídicos ou sociais": e "mulheres estão no meio desse processo" (Women are in the midst of this process), alega MacKinnon. ${ }^{41}$

\footnotetext{
${ }^{36}$ MACKINNON, Are Women Human? and Other International Dialogues, p. 162.

${ }^{37}$ MACKINNON, Are Women Human? and Other International Dialogues, p. 163.

${ }^{38}$ MACKINNON, Are Women Human? and Other International Dialogues, p. 164. Conforme pode-se ler ainda neste capítulo do livro, The New York Times relatou que "pilhas de revistas pornográficas" (piles of pornographic magazines) foram encontradas no quarto de Borislav Herak, o soldado sérvio capturado que tranquilamente admitiu em sua quota de ações militares um número alto de estupros e assassinatos.

${ }^{39}$ MACKINNON, Are Women Human? and Other International Dialogues, p. 164.

${ }^{40}$ MACKINNON, Are Women Human? and Other International Dialogues, p. 3.

${ }^{41}$ MACKINNON, Are Women Human? and Other International Dialogues, p. 3.
} 


\section{À guisa de conclusão}

De distintas perspectivas metodológicas, pode-se compreender que, apesar do impacto dos "corpos que contam" ou dos "corpos que pesam", não se pode entender que o ponto de origem das políticas feministas dos anos 1990 seja o corpo tomado em si mesmo, já que após Simone de Beauvoir o corpo não é um dado natural ou biológico incontestável e, com Butler, lê-se criticamente a lógica universalista do signo Mulheres. Os feminismos dos anos 1990 não assumem o corpo pela dimensão meramente científica ou empírica, ou como o fundamento que sustenta a realidade, já que tal fundamento é sempre instável, de mobilidade constante. O corpo deve ser tomado pelo viés de seu reconhecimento. Conforme Burgos Dias, é pela dimensão corpórea que reconhecemos, percebemos e experimentamos o discurso que se denomina humano, relativo ao lugar da vida que se vive e como se vive ${ }^{42}$. Assim, problematizam-se justamente os corpos que são excluídos do significado de corpos válidos e valiosos, o que os Feminismos dos anos 1990 justamente problematizam.

O que há de específico no discurso feminista assumido por Catharine MacKinnon, que entende estar na defesa de mulheres reais e não abstratas? Em seus textos, conferências e práticas, atuando durante toda uma vida como advogada em favor dos direitos das mulheres, ela questiona a legitimidade do poder patriarcal e propõe revisões às leis. Visa abordar o problema dos direitos e ampliar o alcance da cidadania, de modo que possam se ajustar às experiências das mulheres. Assumir a categoria do humano fora da esquadria normativa masculina que se impõe como categoria substancial garantirá um teor de mais dignidade para as mulheres, no sentido de tornar os direitos humanos também a elas acessíveis, para que suas capacidades efetivas possam ser desenvolvidas. Sobretudo, ela visa deixar bem evidente que a violência sexual, que de forma silenciosa e invisível integra a vida quotidiana das mulheres em supostas democracias contemporâneas, deve ser considerada como factual e degradante, para que se verifiquem mudanças legais tanto em tempos de guerra, quanto em tempos de paz nas democracias reais. Afinal, a violência não se mantém no registro apenas de palavras ou ideias, mas são atos expressivos e performativos.

Contudo, se nós mulheres somos realmente "humanas", na lógica de MacKinnon, podemos ser algo mais ou algo diferente na medida em que esta realidade distorcida em que nos inserimos historicamente não esgota as potencialidades do humano. Ao constatar a violência que recai sobre cada mulher e sobre as mulheres em geral, MacKinnon não pretende render-se ao fato de que todas as possibilidades foram exauridas. Suas orientações são no sentido de se dever buscar instrumentos contra as opressões advindas do Estado, da família, da comunidade, de poderes geradores da opressão feminina. É preciso, então, rever o próprio status de humanidade, para que nós mulheres possamos ser tomadas como humanas. Eis a tarefa dos feminismos contemporâneos.

\section{Referências bibliográficas}

BESUSSI, A.; FACCHI, A. Introduzione all'edizione italiana di: Le donne sono umane?. Bari, Roma: Laterza, 2012.

42 BURGOS DÍAS, “Cruzando líneas. Trazando conexiones”, p. 332. 
. "Introduzione all`edizione italiana di Le donne sono umane?". In: Jura Gentium: Rivista di filosofia del diritto internazionale e della politica globale. v. X1, n. ${ }^{\circ}$ 1, 2014.

BROWN, W. “The Most We Can Hope For...': Human Rights as the Politics of Fatalism”. In: The South Atlantic Quarterly, v. 103, n. 2-3, pp. 451-463, 2004.

BURGOS DÍAZ, E. “Cruzando líneas. Trazando conexiones”. In: Feminismo/s, v. 15, pp. 33-54, 2010.

. "Devenires corporales: como pensar de un outro modo". In: Thémata: Revista de Filosofia, v. 46, pp. 331-343, 2012.

BUTLER, J. Bodies that Matter. On the Discursive Limits of Sex. New York: Routledge, [1993] 2011.

CASTILLO, A. "Lo humano, la violência y las mujeres". In: Archivos de Filosofía, v. 4-5, pp. 31-39, 2009/2010.

COPELON, R. "Terror íntimo: violencia doméstica entendida como tortura”. In: COOK, R. (Ed.). Derechos Humanos de la Mujer. Perspectivas nacionales e internacionales. Bogotá: Profamilia, pp. 110-144, 1997.

COSTA, C. L. “O sujeito no feminismo: revisitando os debates”. In: Cadernos Pagu, n. ${ }^{19}$, pp. 59-90, 2002.

De LARETIS, T. “O sujeito no feminismo. Revisitando os debates". In: Cadernos Pagu, n. 19, pp. 59-90, 2002.

Technologies of Gender: Essays on Theory, Film, and Fiction. Bloomington: Indiana University Press, 1987.

FACCHI, A. "El Pensamiento Feminista sobre el Derecho. Un recorrido desde Carol Gilligan a Tove Stang Dahl”. In: Revista Academia, n. o 6, pp. 27-47, 2005.

FEMENÍAS, M. L. Judith Butler. Introducción a su lectura. Buenos Aires: Siglo XXI Ediciones, 2003.

MACKINNON, C. Are Women Human? and Other International Dialogues. Cambridge, MS: Harvard University Press, 2006.

"Feminism, Marxism, Method and the State: Toward Feminist Jurisprudence". In: Signs, Vol. 8, No. 4, pp. 635-658, 1983.

Only Words. Cambridge, Massachusetts: Harvard University Press, [1993] 1996.

STROSSEN, N. Defending Pornography. Free Speech, Sex, and Fight for Women's Rights. New

York: New York University Press [1995] 2000. 